\title{
Usulan Strategi Peningkatan Loyalitas Pelanggan di Clove Garden Hotel and Residence, Bandung
}

\author{
Proposed Strategy to Enhance Customer Loyalty at Clove Garden Hotel \\ and Residence, Bandung
}

Stephanus Yosua, Yulianti

Program Studi Teknik Industri - Universitas Kristen Maranatha

E-mail: ocu96.sy@gmail.com, yulianti@eng.maranatha.edu

\begin{abstract}
Abstrak
Clove Garden Hotel \& Residence (CGHR) merupakan hotel bintang 4 yang berdiri sejak tahun 2015. Berdasarkan data penyewaan kamar yang tercatat di perusahaan, terlihat rendahnya loyalitas tamu CGHR, yaitu hanya 8,17\% tamu yang melakukan booking berulang. Penelitian ini bertujuan untuk memberikan usulan strategi pada CGHR agar loyalitas tamu hotel dapat meningkat. Data dikumpulkan melalui observasi, wawancara, dan kuesioner. Variabel di kuesioner disusun berdasarkan teori bauran pemasaran dan teori loyalitas. Kuesioner disebarkan kepada 110 tamu hotel yang menginap dan melakukan pemesanan di CGHR. Skor loyalitas taти hotel menjadi variabel dependen dalam pengolahan Regresi Berganda, sedangkan variabel independennya adalah selisih antara data tingkat kepentingan dan kinerja bauran pemasaran. Data tingkat kepentingan dan kinerja bauran pemasaran kemudian diolah juga menggunakan metode Importance Performance Analysis (IPA) dan pengujian hipotesis rata-rata. Informasi mengenai profil tamu hotel digunakan untuk usulan targeting dan positioning, juga mempertajam usulan penelitian. Berdasarkan hasil penelitian, diusulkan agar CGHR mempertimbangkan penggunaan slogan "Comfort, Green Environment, and Pay Less", memberikan kupon diskon untuk menginap berikutnya, membuat daftar menu breakfast harian, menambah jumlah pekerja dan meja receptionist pada peak season, serta memberikan pelatihan kepada satpam sehingga lebih percaya diri ketika berkomunikasi dengan temu hotel.
\end{abstract}

Kata kunci: Loyalitas, bauran pemasaran, regresi berganda, importance-performance analysis, pengujian hipotesis rata-rata

\begin{abstract}
Clove Garden Hotel \& Residence (CGHR) is a 4-star hotel that was established in 2015. Based on room occupancy data recorded in the company, only $8.17 \%$ of guests make repeated bookings, means that CGHR guest loyalty is low. This study aims to propose strategy to CGHR so that CGHR guest loyalty can increase. Data collected through observation, interviews and questionnaires. The variables in the questionnaire arranged based on marketing mix theory and loyalty theory. Questionnaires distributed to 110 hotel guests who stayed and booked at CGHR. In Multiple Regression processing, CGHR guest loyalty scores become the dependent variable, while the independent variable is the difference between the importance data and the performance data from based on marketing mix. Importance data and performance data then processed using Importance Performance Analysis (IPA) method and hypothesis testing for means. Information about hotel guest profiles used for proposed targeting and positioning, also sharpens research proposals. Based on this study, it is proposed that CGHR consider the use of the slogan "Comfort, Green Environment, and Pay Less", provide discount coupons for the next stay, make a list of daily breakfast menus, increase the number of workers and add receptionist tables during peak season, and provide training for security guards so that the security guards more confident when communicating with hotel guests.
\end{abstract}

Keywords: Loyalty, marketing mix, multiple regression, importance-performance analysis, hypothesis testing for means 


\section{Pendahuluan}

Loyalitas adalah komitmen yang dipegang secara mendalam untuk membeli atau mendukung kembali produk atau jasa yang disukai di masa depan meskipun pengaruh situasi dan usaha pemasaran berpotensi menyebabkan pelanggan beralih (Kotler 2009). Karena itu, menjaga dan meningkatkan loyalitas konsumen merupakan hal yang sangat penting bagi para pemilik usaha, sebagai salah satu cara agar dapat tetap bertahan dalam persaingan usaha. Selain melakukan pembelian berulang, konsumen yang loyal juga akan membantu perusahaan dalam mempromosikan usahanya.

Kota Bandung banyak disinggahi oleh wisatawan, baik wisatawan lokal maupun wisatawan mancanegara. Hal ini menyebabkan banyaknya bermunculan penginapan dengan berbagai tipe (hotel, motel, villa, dst) di Bandung, yang siap bersaing satu sama lain dalam mendapatkan konsumen. Clove Garden Hotel \& Residence (CGHR) merupakan salah satu dari sekian banyak hotel bintang 4 yang ada di kota Bandung, yang berdiri sejak tahun 2015 dan saat ini memiliki 145 kamar hotel.

Berdasarkan data dari perusahaan, saat ini jumlah tamu yang melakukan booking berulang di CGHR hanya $8.17 \%$. Angka ini merupakan salah satu indikator dari loyalitas tamu hotel CGHR, dan pihak perusahaan menilai bahwa angka ini terlalu rendah dan perlu ditingkatkan. Pihak perusahaan membutuhkan strategi untuk meningkatkan loyalitas tamu hotel.

\section{Tinjauan Pustaka}

Tinjauan pustaka ini berisi teori-teori yang digunakan dalam penelitian, yang dijadikan dasar kerangka berpikir dan landasan dalam pengolahan data serta penganalisaan hasil pengolahan data.

\subsection{Penelitian Sebelumnya}

Banyak penelitian yang membahas mengenai perhotelan di Indonesia dengan berbagai topik. Setiap wilayah hotel tentunya memberikan pengalaman yang berbeda bagi tiap tamu hotelnya, juga memiliki karakteristik tamu hotel yang berbeda-beda.

Penelitian mengenai hotel di Bandung untuk rentang 5 tahun terakhir bertopik pengaruh kualitas pelayanan terhadap kepuasan tamu hotel, dengan studi kasus di berbagai hotel. Penelitian mengenai hotel di Indonesia namun diluar kota Bandung memiliki topik yang lebih bervariasi, beberapa bertopik mengenai variabel yang berpengaruh terhadap loyalitas tamu hotel seperti penelitian yang dilakukan oleh Winata (2017) yang memberikan kesimpulan bahwa promosi dan lokasi yang signifikan berpengaruh pada loyalitas tamu hotel di kota Medan, dan Stellamaris, Sutanto (2019) yang menyatakan bahwa kualitas pelayanan dan kesesuaian harga yang berpengaruh terhadap loyalitas tamu hotel di kota Surabaya.

Penelitian ini bertujuan mencari variabel yang berpengaruh pada loyalitas tamu hotel di kota Bandung, sebagai perbandingan hasil dengan penelitian serupa yang sudah dilakukan pada kota-kota di Indonesia lainnya.

\subsection{Loyalitas Konsumen}

Pelanggan loyal bukan hanya sumber daya yang sangat berharga, mereka adalah modal perusahaan yang tidak berwujud. Nilai perusahaan secara dramatis meningkat ketika jumlah pelanggan yang loyal meningkat. Hal utama yang harus diperlihatkan oleh perusahaan agar dapat sukses adalah dengan membangun loyalitas konsumen.

Strategi untuk membangun loyalitas konsumen: (Timm, 2001)

1. Perusahaan harus melakukan evaluasi untuk mengetahui hal-hal yang menyebabkan konsumen tidak mau datang kembali dan yang membuat konsumen mau datang kembali menggunakan jasa atau produk perusahaan tersebut

2. Perusahaan harus mengetahui hal-hal yang tidak memuaskan konsumen dan memperbaikinya. 


\section{USULAN STRATEGI PENINGKATAN LOYALITAS PELANGGAN (Stephanus Y., dkk.)}

3. Perusahaan harus memperlakukan konsumen seakan-akan mereka lebih dari konsumen lain. Namun pada kenyataannya perusahaan melakukan hal yang sama kepada konsumen lain.

4. Perusahaan harus memberi nilai tambah kepada konsumen, seperti pengalaman yang tidak terlupakan, jaminan dan garansi, kepercayaan dan lain-lain.

5. Perusahaan harus memberi informasi terbaru kepada seluruh konsumen, dengan jelas dan dapat dimengerti oleh konsumen.

6. Perusahaan harus menunjukkan kepribadian yang lebih baik kepada konsumen, melalui soft skills pekerja.

7. Perusahaan harus memberi kenyamanan lebih kepada konsumen melalui penggunaan produk atau jasa yang ditawarkan perusahaan.

\subsection{Regresi Berganda}

Regresi berganda adalah teknik statistika yang digunakan untuk meneliti hubungan antara 1 variabel dependen (kriteria) dan beberapa (dua atau lebih) variabel independen (prediktor), juga untuk memprediksi 1 variabel dependen. (Hair, 2010)

Penggunaan utama Regresi Berganda adalah :

1. Mengetahui kemampuan variabel independen untuk memprediksi variabel dependen. Keakuratan prediksi sangat penting untuk memastikan validitas variabel independen.

2. Menilai derajat dan karakter hubungan antara variabel dependen dan independen melalui persamaan yang terbentuk : kekuatan, arah, tanda dan signifikansi variabel independen melalui koefisien regresi dari tiap variabel independen.

Rumus dasar:

$\mathrm{Y}=\mathrm{b}_{0}+\mathrm{b}_{1} \cdot \mathrm{X}_{1}+\mathrm{b}_{2} . \mathrm{X}_{2}+\ldots+\mathrm{b}_{\mathrm{n}} . \mathrm{X}_{\mathrm{n}}+\mathrm{e}$

Dimana:

Y : prediksi variabel dependen

$\mathrm{b}_{0} \quad$ : intersep

$\mathrm{b}_{1} \cdot \mathrm{X}_{1} \quad$ : efek linier dari $\mathrm{X}_{1}$

$\mathrm{b}_{2} . \mathrm{X}_{2}$ : efek linier dari $\mathrm{X}_{2}$

Koefisien korelasi (b) dapat menunjukkan tipe hubungan (positif dan negatif) antara variabel independen dan dependen dan kekuatan hubungan antara variabel independen dan dependen.

\subsection{Pengujian Hipotesis Rata-rata}

Uji hipotesis merupakan prosedur untuk pengambilan keputusan secara statistika, untuk memutuskan apakah menerima atau menolak hipotesis mengenai parameter yang telah dirumuskan. (Lind, 2012). Salah satu bentuk pengujian hipotesis adalah pengujian hipotesis rata-rata dari 2 populasi independen.

$$
\begin{array}{ll}
\mathrm{H}_{\mathrm{o}} & : \mu_{1}-\mu_{2}=\mathrm{d}_{0} \\
\mathrm{H}_{1} & : \mu_{1}-\mu_{2} \neq \mathrm{d}_{0}
\end{array} \quad \text { atau } \quad \mu_{1}-\mu_{2}>\mathrm{d}_{0} \quad \text { atau } \quad \mu_{1}-\mu_{2}<\mathrm{d}_{0}
$$

Rumus yang digunakan untuk ukuran sampel minimal 30:

$$
\mathrm{Z}=\frac{\left(\overline{\mathrm{x}}_{1}-\overline{\mathrm{x}}_{2}\right)-\left(\mu_{1}-\mu_{2}\right)}{\sqrt{\frac{\mathrm{s}_{1}^{2}}{\mathrm{n}_{1}}+\frac{\mathrm{s}_{2}^{2}}{\mathrm{n}_{2}}}}
$$

Dimana :

$\mu$ : rata-rata populasi

$\overline{\mathrm{X}}$ : rata-rata sampel

$\mathrm{s}^{2}$ : variansi sampel

$\mathrm{n}$ : ukuran sampel

\subsection{Importance Performance Analysis}

Metode Importance Performance Analysis bertujuan untuk mengukur hubungan antara persepsi konsumen dan prioritas peningkatan kualitas produk/jasa. Analisis perbandingan performance (yang menunjukan kinerja suatu perusahaan atau produk) dengan importance (yang menunjukan 
harapan responden yang terkait dengan variabel yang diteliti) digambarkan dalam diagram kartesius, membentuk suatu bangun yang dibagi menjadi empat bagian yang dibatasi oleh dua buah garis yang berpotongan tegak lurus pada titik (x,y). (Supranto, 2001)

Sumbu x menunjukkan rata-rata dari rata-rata performansi dari produk atau perusahaan terhadap suatu variabel dan sumbu y menunjukkan rata-rata dari tingkat kepentingan suatu variabel. Tiap kuadran menggambarkan terjadinya suatu kondisi yang berbeda dengan kuadran lainnya.

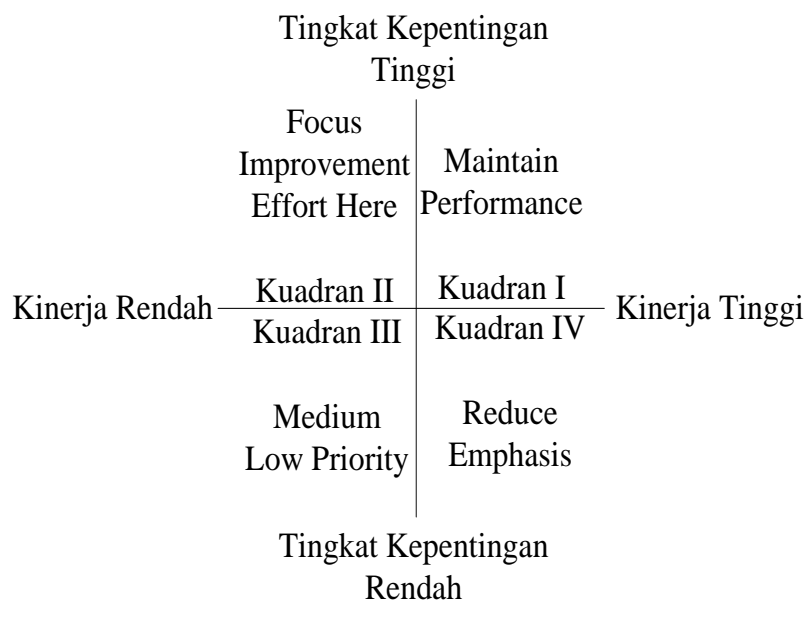

Gambar 1. Matrix Importance Performance Analysis

Keterangan:

I : Pertahankan Prestasi/Maintain Performance

Faktor-faktor yang terletak pada kuadran ini dianggap penting sebagai faktor penunjang bagi kepuasan konsumen sehingga pihak pengelola berkewajiban memastikan bahwa kinerja dari usaha yang dikelola dapat terus dipertahankan

II : Prioritas Utama/Fokus Improvement Effort Here

Faktor-faktor yang terletak pada kuadran ini dianggap sebagai yang penting oleh konsumen namun kondisi pada saat ini kinerja dinilai belum mencukupi sehingga pihak pengelola berkewajiban mengalokasikan sumber daya yang memadai untuk meningkatkan kinerja berbagai faktor tersebut

III : Prioritas Rendah/Medium Low Priority

Faktor-faktor yang terletak pada kuadran ini mempunyai tingkat kinerja yang rendah dan sekaligus tidak dianggap terlalu penting bagi konsumen, sehingga pihak pengelola tidak perlu memprioritaskan pada faktor-faktor tersebut.

IV : Berlebihan/Reduce Emphasis

Faktor-faktor yang terletak pada kuadran ini dianggap tidak terlalu penting sehingga pihak pengelola tidak perlu mengalokasikan sumber daya terlalu banyak untuk faktor-faktor tersebut.

\section{Pembahasan}

\subsection{Penentuan Variabel Penelitian}

Penelitian ini menggunakan teori yang dikemukakan oleh Paul R. Timm, Ph.D. dengan Philip Kotler (2001), yang menyatakan bahwa untuk membangun loyalitas konsumen dibutuhkan 7 strategi, salah satunya adalah memberikan kepuasan kepada konsumen.

Walaupun Timm menyatakan adanya 7 strategi untuk membangun loyalitas konsumen, namun penelitian ini dibatasi hanya meneliti salah satu strategi saja yaitu pengaruh kepuasan konsumen terhadap loyalitas konsumen, dimana loyalitas konsumen ditunjukkan dengan minat untuk menginap kembali dan minat untuk merekomendasikan pada orang lain. 


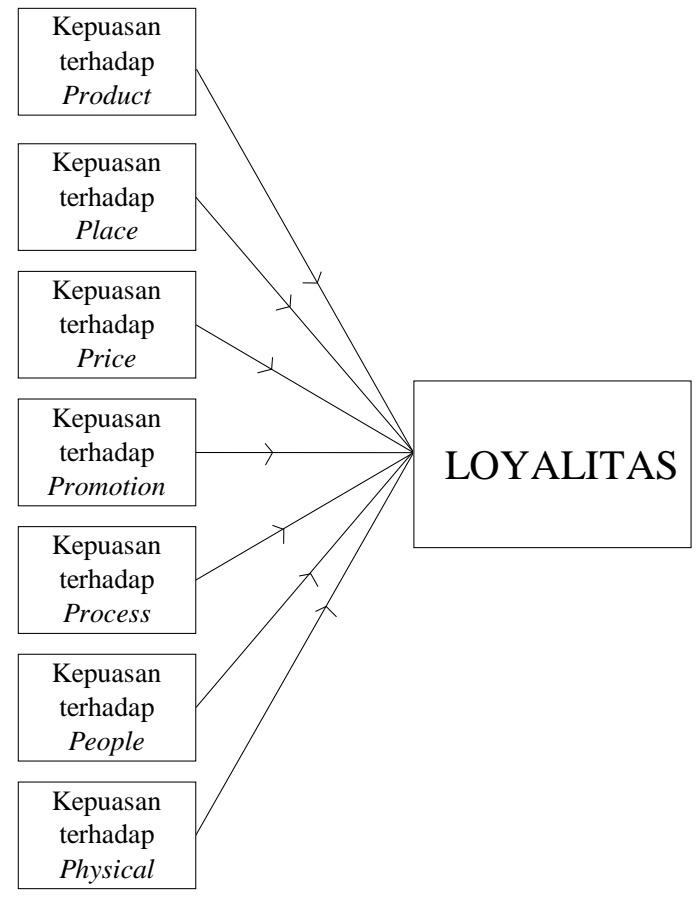

Gambar 2. Model Penelitian

Untuk pengukuran kepuasan konsumen, digunakan variabel bauran pemasaran 7P yaitu (product, price, promotion, place, people, process, physical evidence). Berikut adalah variabel penelitian yang digunakan:

Variabel bauran pemasaran:

Var 1 : Kebersihan kamar

Var 2 : Variasi jenis kamar

Var 3 : Kesejukan kamar

Var 4 : Pencahayaan kamar

Var 5 : Aroma kamar

Var 6 : Penataan kamar

Var 7 : Kelengkapan fasilitas kamar mandi (handuk, sikat gigi, dll)

Var 8 : Kelengkapan fasilitas kamar (TV, sandal, kulkas, dll)

Var 9 : Kenyamanan tempat duduk di restaurant

Var 10 : Kenyamanan pencahayaan di restaurant

Var 11 : Kenyamanan suhu di restaurant

Var 12 : Kelezatan rasa breakfast

Var 13 : Variasi menu breakfast

Var 14 : Toleransi pihak hotel menentukan waktu check out

Var 15: Kejelasan petunjuk jalan menuju hotel

Var 16 : Kemudahan parkir

Var 17 : Keamanan tempat parkir

Var 18 : Keramahan receptionist

Var 19 : Kecepatan receptionist dalam membantu tamu

Var 20: Ketepatan receptionist

Var 21 : Kemampuan komunikasi receptionist

Var 22 : Kesopanan receptionist terhadap tamu

Var 23 : Kerapihan pakaian receptionist

Var 24 : Keramahan satpam

Var 25: Kecepatan satpan dalam membantu memarkirkan kendaraan

Var 26 : Kemampuan komunikasi satpam

Var 27 : Kesopanan satpam terhadap tamu

Var 28 : Kerapihan pakaian satpam 
Var 29 : Kesesuaian tarif hotel dengan fasilitas yang diberikan

Var 30 : Frekwensi diberikannya diskon

Var 31 : Kemenarikan promosi melalui instagram

Var 32: Kemudahan check in

Var 33 : Kemudahan check out

Var 34 : Kebersihan peralatan makan

Var 35 : Kebersihan ruang tunggu (lobby)

Var 36 : Kenyamanan kursi di ruang tunggu (lobby)

Variabel loyalitas:

1. Minat untuk menggunakan jasa CGHR di masa yang akan datang.

2. Minat untuk merekomendasikan CGHR kepada kerabat.

Sedangkan untuk tujuan segmentasi, targeting dan positioning disusun pertanyaan berkaitan dengan jenis kelamin, usia, kota asal, pekerjaan, penghasilan, sumber informasi tentang hotel, media sosial yang digunakan, jenis pembayaran yang biasa dilakukan, bank yang digunakan, promo hotel yang disukai, proses pemesanan yang disukai, perbandingan tarif hotel dan perbandingan pemandangan hotel.

\subsection{Pengumpulan Data}

Dalam penelitian ini, data dikumpulkan melalui wawancara pada pemilik hotel dan kuesioner pada tamu hotel. Kuesioner penelitian terdiri dari 3 bagian yaitu:

1. Bagian pertama berisi data responden untuk segmentasi-targeting-positioning.

2. Bagian kedua berisi pengukuran tingkat kepentingan konsumen (skala Likert: Sangat Tidak Penting hingga Sangat Penting / 1 hingga 4) dan pengukuran kinerja CGHR berdasarkan variabel bauran pemasaran skala Likert: Sangat Tidak Baik hingga Sangat Baik / 1 hingga 4).

3. Bagian ketiga berisi pengukuran tingkat loyalitas konsumen (skala Likert: Sangat Tidak Setuju hingga Sangat Setuju / 1 hingga 4)

Jumlah sampel minimal dihitung dengan menggunakan rumus Paul Leedy

$\mathrm{n}=\left(\frac{\mathrm{Z}_{\alpha / 2}}{\mathrm{e}}\right)^{2} \cdot \mathrm{P} \cdot(1-\mathrm{P})$

Dimana :

$\mathrm{n}=$ Ukuran sampel.

$\mathrm{Z}=$ nilai dari tabel Normal.

$\mathrm{e}=$ Sampling error maksimum yang diperkenankan

$\alpha=$ Tingkat ketelitian (5\%)

$\mathrm{P}=$ Proporsi populasi yang akan diteliti. Jika tidak dapat memperkirakan proporsi populasi, maka ditentukan $\mathrm{P}=0.5$.

Sehingga :

$\mathrm{N}=\left(\frac{1.96}{0.01}\right)^{2} \cdot 0.5 \cdot(1-0.5)=96.04$ responden $\approx 97$ responden

Jumlah responden minimal adalah 97 responden, namun dengan pertimbangan kemungkinan adanya pengisian kuesioner yang tidak lengkap maka akan disebarkan kuesioner sebanyak 110 kuesioner, namun hanya 106 kuesioner yang diisi secara lengkap.

Kuesioner disebarkan dengan teknik sampling purposive, pada tamu hotel yang menginap dan melakukan pemesanan di CGHR, serta menggunakan kendaraan pribadi untuk ke CGHR. 


\subsection{Pengolahan Kuesioner Penelitian}

Data hasil penyebaran kuesioner yang sudah terbukti valid dan reliabel, diolah sebagai berikut:

1. Profil responden dari bagian pertama dihitung nilai persentasenya untuk masing-masing pilihan jawaban.

2. Data tingkat kepentingan tamu hotel dan tingkat kinerja CGHR diolah dengan metode Importance Performance Analysis dan pengujian hipotesis rata-rata.

3. Selisih data tingkat kepentingan dan tingkat kinerja dijadikan variabel independen, sedangkan rata-rata tingkat loyalitas dijadikan variabel dependen. Kedua data tersebut diuji asumsi klasik sebelum diolah dengan metode Regresi Berganda. Uji asumsi klasik yang dilakukan terdiri dari uji kenormalan, uji linearity, uji homoscedasticity, uji multicollinearity dan uji autokorelasi.

4. Data loyalitas tamu hotel dihitung rata-ratanya untuk mengetahui tingkat loyalitas konsumen.

\subsubsection{Importance Performance Analysis (IPA)}

Dalam penelitian ini, metode IPA digunakan untuk mengetahui prioritas perbaikan yang harus dilakukan oleh CGHR, melalui plotting nilai kepentingan (sumbu Y) dan nilai kinerja (sumbu X) masing-masing variabel bauran pemaaran ke dalam 4 kuadran. Kuadran terbagi berdasarkan nilai rata-rata tingkat kepentingan dan rata-rata tingkat kinerja untuk seluruh variabel yaitu 3.315 (kepentingan) dan 2.917 (kinerja)

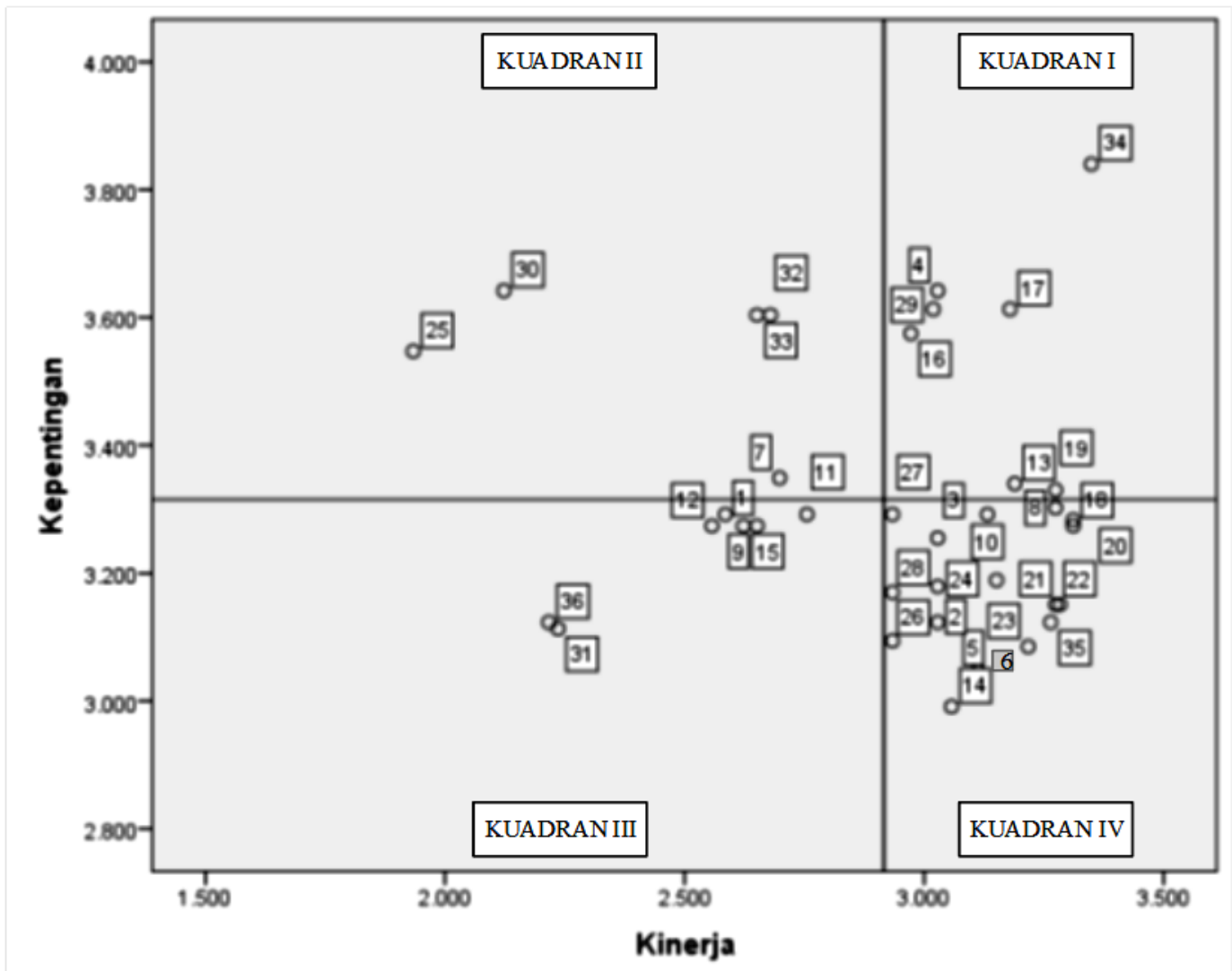

Gambar 3. Matriks Importance-Performance Analysis

Berdasarkan metode IPA, variabel bauran pemasaran yang membutuhkan prioritas perbaikan utama adalah variabel yang berada pada kuadran II (sejumlah 5 variabel) karena variabel ini memiliki nilai kinerja di bawah rata-rata padahal nilai kepentingan konsumen diatas rata-rata. Prioritas perbaikan selanjutnya adalah variabel pada kuadran III (sejumlah 7 variabel), karena walaupun nilai kepentingannya dibawah rata-rata namun masih diatas 3 dan nilai kinerjanya di bawah ratarata. Selanjutnya perbaikan dilakukan pada variabel bauran pemasaran di kuadran I (sejumlah 7 variabel) karena walaupun nilai kinerjanya di atas rata-rata namun masih berada dibawah nilai kepentingan. Perbaikan terakhir dilakukan pada variabel bauran pemasaran di kuadran IV (sejumlah 17 variabel). 


\subsubsection{Pengujian Hipotesis Rata-rata}

Pengujian hipotesis rata-rata pada penelitian ini digunakan untuk mengetahui apakah terdapat kesenjangan yang signifikan secara statistik antara tingkat kepentingan tamu hotel dan tingkat kinerja yang diberikan oleh CGHR.

Struktur Hipotesis:

Ho : $\mu_{1}=\mu_{2}$

(tidak ada perbedaan antara rata-ratabtingkat kinerja CGHR dengan rata-ratatingkat kepentingan tamu hotel, sehingga tamu hotel puas)

$\mathrm{Hi}: \mu_{1}<\mu_{2}$

(rata-rata tingkat kinerja CGHR lebih rendah daripada rata-rata tingkat kepentingan tamu hotel, sehingga tamu hotel tidak puas)

Keterangan :

Populasi 1 menunjukkan tingkat kinerja

Populasi 2 menunjukkan tingkat kepentingan

Taraf nyata: $\alpha=0.05$

Statistik uji: Uji Normal

$$
Z_{\text {hitung }}=Z=\frac{\left(\bar{x}_{1}-\bar{x}_{2}\right)-\left(\mu_{1}-\mu_{2}\right)}{\sqrt{\frac{\mathrm{s}_{1}^{2}}{\mathrm{n}_{1}}+\frac{\mathrm{s}_{2}^{2}}{\mathrm{n}_{2}}}}
$$

Wilayah Kritis: dari tabel distribusi Normal dengan $\alpha=0.05=-1.645$

Kesimpulan: Tolak Ho jika nilai $\mathrm{Z}$ hitung $<-1.645$

Berikut adalah hasil pengujian hipotesis rata-rata 39 variabel bauran pemasaran:

Tabel 1. Hasil Pengujian Hipotesis Rata-rata

\begin{tabular}{|c|c|c|c|c|c|c|c|}
\hline \multirow[t]{2}{*}{ Variabel } & \multicolumn{2}{|c|}{ Tingkat Kinerja } & \multicolumn{2}{|c|}{$\begin{array}{c}\text { Tingkat } \\
\text { Kepentingan }\end{array}$} & \multirow{2}{*}{$\begin{array}{c}\mathrm{Z} \\
\text { Hitung }\end{array}$} & \multirow[t]{2}{*}{ Keputusan } & \multirow[t]{2}{*}{ Kesimpulan } \\
\hline & $\overline{\mathrm{x}}_{1}$ & $\mathrm{~s}_{1}$ & $\overline{\mathrm{x}}_{2}$ & $\mathrm{~s}_{2}$ & & & \\
\hline 1 & 2.585 & 0.729 & 3.292 & 0.457 & -8.47 & Tolak Ho & Tidak Puas \\
\hline 2 & 3.028 & 0.291 & 3.179 & 0.385 & -3.217 & Tolak Ho & Tidak Puas \\
\hline 3 & 3.028 & 0.291 & 3.255 & 0.438 & -4.433 & Tolak Ho & Tidak Puas \\
\hline 4 & 3.028 & 0.291 & 3.642 & 0.482 & -11.21 & Tolak Ho & Tidak Puas \\
\hline 5 & 3.028 & 0.291 & 3.123 & 0.613 & -1.432 & Terima Ho & Puas \\
\hline 6 & 3.113 & 0.484 & 3.047 & 0.667 & 0.8245 & Terima Ho & Puas \\
\hline 7 & 2.698 & 0.604 & 3.349 & 0.535 & -8.302 & Tolak Ho & Tidak Puas \\
\hline 8 & 3.274 & 0.61 & 3.302 & 0.461 & -0.381 & Terima Ho & Puas \\
\hline 9 & 2.651 & 0.517 & 3.274 & 0.448 & -9.37 & Tolak Ho & Tidak Puas \\
\hline 10 & 3.132 & 0.518 & 3.292 & 0.457 & -2.391 & Tolak Ho & Tidak Puas \\
\hline 11 & 2.755 & 0.814 & 3.292 & 0.457 & -5.929 & Tolak Ho & Tidak Puas \\
\hline 12 & 2.557 & 0.794 & 3.274 & 0.448 & -8.099 & Tolak Ho & Tidak Puas \\
\hline 13 & 3.189 & 0.732 & 3,34 & 0.514 & -1.737 & Tolak Ho & Tidak Puas \\
\hline 14 & 3.057 & 0.688 & 2.991 & 0.64 & 0.7238 & Terima Ho & Puas \\
\hline 15 & 2.623 & 0.878 & 3.274 & 0.448 & -6.801 & Tolak Ho & Tidak Puas \\
\hline 16 & 2.972 & 0.577 & 3.575 & 0.632 & -7.268 & Tolak Ho & Tidak Puas \\
\hline 17 & 3.179 & 0.385 & 3.613 & 0.527 & -6.845 & Tolak Ho & Tidak Puas \\
\hline
\end{tabular}


Tabel 1. Hasil Pengujian Hipotesis Rata-rata (Lanjutan)

\begin{tabular}{|c|c|c|c|c|c|c|c|}
\hline \multirow{2}{*}{ Variabel } & \multicolumn{2}{|c|}{ Tingkat Kinerja } & \multicolumn{2}{c|}{$\begin{array}{c}\text { Tingkat } \\
\text { Kepentingan }\end{array}$} & \multirow{2}{*}{$\begin{array}{l}\text { Z } \\
\text { Hitung }\end{array}$} & Keputusan & Kesimpulan \\
\cline { 2 - 5 } & $\overline{\mathrm{x}}_{1}$ & $\mathrm{~s}_{1}$ & $\overline{\mathrm{x}}_{2}$ & $\mathrm{~s}_{2}$ & & \\
\hline 18 & 3.311 & 0.523 & 3.274 & 0.561 & 0.5064 & Terima Ho & Puas \\
\hline 19 & 3.274 & 0.594 & 3,33 & 0.547 & -0.721 & Terima Ho & Puas \\
\hline 20 & 3.311 & 0.465 & 3.283 & 0.453 & 0.4489 & Terima Ho & Puas \\
\hline 21 & 3.283 & 0.565 & 3.151 & 0.36 & 20.304 & Terima Ho & Puas \\
\hline 22 & 3.274 & 0.448 & 3.151 & 0.409 & 20.812 & Terima Ho & Puas \\
\hline 23 & 3.217 & 0.458 & 3.085 & 0.439 & 21.438 & Terima Ho & Puas \\
\hline 24 & 3.151 & 0.728 & 3.189 & 0.5 & -0.44 & Terima Ho & Puas \\
\hline 25 & 1.934 & 0.843 & 3.547 & 0.604 & -16.02 & Tolak Ho & Tidak Puas \\
\hline 26 & 2.934 & 0.666 & 3.094 & 0.489 & -2 & Tolak Ho & Tidak Puas \\
\hline 27 & 2.934 & 0.666 & 3.292 & 0.477 & -4.505 & Tolak Ho & Tidak Puas \\
\hline 28 & 2.943 & 0.566 & 3,17 & 0.654 & -2.694 & Tolak Ho & Tidak Puas \\
\hline 29 & 3.019 & 0.73 & 3.613 & 0.545 & -6.718 & Tolak Ho & Tidak Puas \\
\hline 30 & 2.123 & 0.891 & 3.642 & 0.555 & -14.89 & Tolak Ho & Tidak Puas \\
\hline 31 & 2.236 & 0.811 & 3.113 & 0.484 & -9.56 & Tolak Ho & Tidak Puas \\
\hline 32 & 2.679 & 0.737 & 3.604 & 0.491 & -10.74 & Tolak Ho & Tidak Puas \\
\hline 33 & 2.651 & 0.648 & 3.604 & 0.491 & -12.06 & Tolak Ho & Tidak Puas \\
\hline 34 & 3.349 & 0.535 & 3,84 & 0.369 & -7.771 & Tolak Ho & Tidak Puas \\
\hline 35 & 3.264 & 0.54 & 3.123 & 0.452 & 20.701 & Terima Ho & Puas \\
\hline 36 & 2,217 & 0.793 & 3.123 & 0.452 & -10.22 & Tolak Ho & Tidak Puas \\
\hline & & & & & & & \\
\hline
\end{tabular}

Hasil pengujian hipotesis rata-rata diatas menunjukkan bahwa dari 36 variabel bauran pemasaran, kurang dari separuhnya yaitu hanya 12 variabel yang telah memuaskan tamu hotel, dan variabel yang paling belum memuaskan tamu hotel adalah variabel 25 yaitu Kecepatan satpam dalam membantu memarkirkan kendaraan. Perbaikan akan berfokus pada variabel yang paling belum memuaskan konsumen, variabel dengan nilai $\mathrm{Z}$ hitung terendah.

\subsubsection{Pengujian Asumsi Klasik}

Sebelum metode Regresi Berganda dilakukan, perlu dilakukan pengujian asumsi klasik untuk memastikan ketepatan penggunaan variabel independen dan dependen untuk diolah dengan metode Regresi Berganda. Pengujian asumsi klasik dilakukan pada variabel dependen (rata-rata nilai dari ketiga variabel loyalitas tamu hotel) dan variabel independen (variabel kepuasan tamu hotel yang dinyatakan dengan selisih antara variabel kepentingan dan variabel kinerja).

Pengujian asumsi klasik yang digunakan sebelum Regresi Berganda adalah uji kenormalan, uji linearity, uji homoscedasticity, uji multicollinearity dan uji autokorelasi, dan hasilnya menyisakan 18 variabel independen yang dapat diolah dengan metode Regresi Berganda, yaitu:

Tabel 2. Variabel Independen yang Lolos Uji Asumsi Klasik

\begin{tabular}{|c|c|c|}
\hline No & $\begin{array}{c}\text { No } \\
\text { Variabel }\end{array}$ & Variabel yang Digunakan Untuk Regresi Berganda \\
\hline 1 & 4 & Pencahayaan kamar \\
\hline 2 & 5 & Aroma kamar \\
\hline 3 & 6 & Penataan kamar \\
\hline 4 & 11 & Kenyamanan suhu di restaurant \\
\hline 5 & 13 & Variasi menu breakfast \\
\hline
\end{tabular}


JOURNAL OF INTEGRATED SYSTEM VOL 2. NO. 2, DESEMBER 2019: 208-225

Tabel 2. Variabel Independen yang Lolos Uji Asumsi Klasik (Lanjutan)

\begin{tabular}{|c|c|c|}
\hline No & $\begin{array}{c}\text { No } \\
\text { Variabel }\end{array}$ & Variabel yang Digunakan Untuk Regresi Berganda \\
\hline 6 & 17 & Keamanan tempat parkir \\
\hline 7 & 19 & Kecepatan receptionist dalam membantu tamu \\
\hline 8 & 20 & Ketepatan receptionist \\
\hline 9 & 23 & Kerapihan pakaian receptionist \\
\hline 10 & 25 & Kemampuan komunikasi satpam \\
\hline 11 & 26 & Kerapanan satpam terhadap tamu \\
\hline 12 & 27 & Frekuensian satpam \\
\hline 13 & 28 & Kemenarikannya diskon \\
\hline 14 & 30 & Kemudahan check in \\
\hline 15 & 31 & Kemudahan check out \\
\hline 16 & 32 & Kebersihan ruang tunggu (lobby) \\
\hline 17 & 33 &
\end{tabular}

\subsubsection{Regresi Berganda}

Pengolahan Regresi Berganda dilakukan pada rata-rata nilai dari ketiga variabel loyalitas tamu hotel sebagai variabel dependen dan 18 variabel kepuasan tamu hotel yang lolos pengujian asumsi klasik sebagai variabel independen.

\section{- Analysis of Variance (ANOVA)}

Untuk memastikan ketepatan penggunaan Regresi Berganda untuk data penelitian ini, dilakukan pengujian Analysis of Variance (ANOVA), sebagai berikut:

Tabel 3. Hasil Pengujian ANOVA

ANOVA $^{\mathrm{a}}$

\begin{tabular}{|ll|r|r|r|r|r|}
\hline \multicolumn{1}{|c|}{} & \multicolumn{1}{c|}{$\begin{array}{c}\text { Sum of } \\
\text { Squares }\end{array}$} & df & Mean Square & \multicolumn{1}{c|}{$\mathrm{F}$} & Sig. \\
\hline 1 & Regression & 19,366 & 1 & 19,366 & 94,919 &, $000^{\mathrm{b}}$ \\
& Residual & 21,219 & 104 &, 204 & & \\
& Total & 40,585 & 105 & & & \\
\hline 2 & Regression & 25,888 & 2 & 12,944 & 90,717 &, $000^{\mathrm{C}}$ \\
& Residual & 14,697 & 103 &, 143 & & \\
& Total & 40,585 & 105 & & & \\
\hline 3 & Regression & 28,257 & 3 & 9,419 & 77,935 &, $000^{\mathrm{d}}$ \\
& Residual & 12,328 & 102 &, 121 & & \\
& Total & 40,585 & 105 & & & \\
\hline 4 & Regression & 29,070 & 4 & 7,267 & 63,742 &, $000^{\mathrm{e}}$ \\
& Residual & 11,515 & 101 &, 114 & & \\
& Total & 40,585 & 105 & & & \\
\hline
\end{tabular}

a. Dependent Variable: Loyalitas

b. Predictors: (Constant), KemampuanKomunikasiSatpam

c. Predictors: (Constant), KemampuanKomunikasiSatpam, VariasiMenuBreakfast

d. Predictors: (Constant), KemampuanKomunikasiSatpam, VariasiMenuBreakfast, Kemudahancheckln

e. Predictors: (Constant), KemampuanKomunikasiSatpam, VariasiMenuBreakfast, Kemudahancheckln, FrekuensiDiberikannyaDiskon 
Ho : variabel kepuasan tamu hotel tidak mempengaruhi variabel loyalitas.

Hi : variabel kepuasan tamu hotel mempengaruhi variabel loyalitas.

Keputusan: terima Ho jika nilai Sig. > 0.05 .

Berdasarkan metode stepwise pada pengolahan SPSS, digunakan model yang keempat, dengan nilai Sig. $<0.05$, sehingga artinya Tolak Ho, penggunaan Regresi Berganda untuk penelitian ini tepat, karena variabel kepuasan tamu hotel mempengaruhi variabel loyalitas.

\section{- Model Summary}

Tabel 4. Model Summary

Model Summary ${ }^{e}$

\begin{tabular}{|l|l|r|r|r|r|}
\hline Model & R & R Square & \multicolumn{1}{c|}{$\begin{array}{c}\text { Adjusted R } \\
\text { Square }\end{array}$} & $\begin{array}{c}\text { Std. Error of } \\
\text { the Estimate }\end{array}$ & $\begin{array}{l}\text { Durbin- } \\
\text { Watson }\end{array}$ \\
\hline 1 & $.691^{\mathrm{a}}$ & .477 & .472 & .451694 & \\
2 & $.799^{\mathrm{b}}$ & .638 & .631 & .377738 & \\
3 & $.834^{\mathrm{C}}$ & .696 & .687 & .347647 & \\
\hline 4 & $.846^{\mathrm{d}}$ & .716 & .705 & .337657 & 2.058 \\
\hline
\end{tabular}

a. Predictors: (Constant), KemampuanKomunikasiSatpam

b. Predictors: (Constant), KemampuanKomunikasiSatpam, VariasiMenuBreakfast

c. Predictors: (Constant), KemampuanKomunikasiSatpam, VariasiMenuBreakfast, Kemudahancheckln

d. Predictors: (Constant), KemampuanKomunikasiSatpam, VariasiMenuBreakfast, KemudahanCheckln, FrekuensiDiberikannyaDiskon

e. Dependent Variable: Loyalitas

Model keempat menghasilkan nilai koefisien korelasi (R) positif yang kuat yaitu sebesar 0.846, artinya keempat variabel kepuasan yaitu variabel Kemampuan Komunikasi Satpam, Variasi Menu Breakfast, Kemudahan Check in dan Frekwensi Diberikannya Diskon memberika pengaruh positif pada Loyalitas Konsumen.

Nilai koefisien determinasi $\left(\mathrm{R}^{2}\right)$ sebesar 0.716 , artinya sebesar $71.6 \%$ dari loyalitas konsumen CGHR dapat dijelaskan oleh keempat variabel kepuasan, sedangkan sisanya sebesar $28.4 \%$ dijelaskan oleh variabel lain yang tidak diteliti dalam penelitian ini.

\section{- Uji t}

Uji t digunakan untuk mengetahui variabel-variabel kepuasan apakah yang secara statistik signifikan mempengaruhi loyalitas tamu hotel. Pengujian dilakukan terhadap koefisien regresi dari keempat variabel kepuasan.

$\mathrm{H}_{0}: \beta_{\mathrm{i}}=0$

$\mathrm{H}_{1}: \beta_{\mathrm{i}} \neq 0$

Keputusan: terima Ho jika nilai Sig. $>0.025$.

Pada model keempat Tabel 6 dibawah, seluruh nilai Sig. dari keempat variabel kepuasan memiliki nilai dibawah 0.025 , artinya seluruh variabel kepuasan tersebut secara statistik signifikan berpengaruh terhadap variabel loyalitas. 
Tabel 5. Coefficients

\begin{tabular}{|c|c|c|c|c|c|c|c|c|}
\hline \multicolumn{9}{|c|}{ Coefficients $^{a}$} \\
\hline \multirow[b]{2}{*}{ Model } & & \multicolumn{2}{|c|}{ Unstandardized Coefficients } & \multirow{2}{*}{$\begin{array}{c}\begin{array}{c}\text { Standardized } \\
\text { Coefficients }\end{array} \\
\text { Beta }\end{array}$} & \multirow[b]{2}{*}{$t$} & \multirow[b]{2}{*}{ Sig. } & \multicolumn{2}{|c|}{ Collinearity Statistics } \\
\hline & & $\mathrm{B}$ & Std. Error & & & & Tolerance & VIF \\
\hline \multirow[t]{2}{*}{1} & (Constant) & 2,929 & .045 & & 65,625 &, 000 & & \\
\hline & $\begin{array}{l}\text { KemampuanKomunikasi } \\
\text { Satpam }\end{array}$ &, 497 &, 051 & 691 & 9,743 &, 000 & 1,000 & 1,000 \\
\hline \multirow[t]{3}{*}{2} & (Constant) & 2,952 & 037 & & 78,763 &, 000 & & \\
\hline & $\begin{array}{l}\text { KemampuanKomunikasi } \\
\text { Satpam }\end{array}$ &, 356 &, 048 &, 494 & 7,487 &, 000 & 806 & 1,240 \\
\hline & VariasiMenuBreakfast &, 304 &, 045 &, 446 & 6,761 &, 000 &, 806 & 1,240 \\
\hline \multirow[t]{4}{*}{3} & (Constant) & 3,104 &, 049 & & 63,850 &, 000 & & \\
\hline & $\begin{array}{l}\text { KemampuanKomunikasi } \\
\text { Satpam }\end{array}$ & ,291 &, 046 &, 405 & 6,320 &, 000 &, 726 & 1,378 \\
\hline & VariasiMenuBreakfast &, 255 &, 043 &, 375 & 5,955 &, 000 &, 753 & 1,329 \\
\hline & KemudahanCheckln &, 183 &, 041 &, 278 & 4,427 &, 000 &, 756 & 1,323 \\
\hline \multirow[t]{5}{*}{$\overline{74}$} & (Constant) & $\overline{\overline{3,226}}$ & 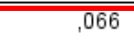 & & 49,097 & $\overline{0.000}$ & & \\
\hline & $\begin{array}{l}\text { KemampuanKomunikasi } \\
\text { Satpam }\end{array}$ & 235 &, 050 &, 326 & 4,745 &, 000 &, 594 & 1,685 \\
\hline & VariasiMenuBreakfast &, 257 &, 042 &, 377 & 6,173 &, 000 &, 753 & 1,329 \\
\hline & KemudahanCheckln & , 158 &, 041 &, 240 & 3,836 &, 000 &, 717 & 1,394 \\
\hline & $\begin{array}{l}\text { FrekuensiDiberikannyaDi } \\
\text { skon }\end{array}$ &, 101 &, 038 &, 173 & 2,669 &, 009 &, 669 & 1,495 \\
\hline
\end{tabular}

a. Dependent Variable: Loyalitas

Persamaan regresi yang terbentuk untuk penelitian ini adalah:

$\mathrm{Y}=$ Loyalitas Konsumen $=3.226+0.235$ Kemampuan Komunikasi Satpam +0.257 Variasi Menu Breakfast + 0.158 Kemudahan Check In + 0.101 Frekuensi Diberikannya Diskon

Seluruh nilai koefisien regresi variabel kepuasan bernilai positif, artinya seluruh variabel kepuasan tersebut memiliki pengaruh positif pada loyalitas. Semakin tinggi nilai kepuasan tamu hotel pada variabel tersebut maka loyalitas tamu hotel juga akan semakin tinggi.

Hasil pengolahan regresi berganda di atas menunjukkan bahwa loyalitas konsumen tamu hotel di CGHR dipengaruhi oleh variabel manusia, produk dan promosi. Hasil penelitian ini berbeda dengah kedua hasil penelitian mengenai hotel sebelumnya yang dilakukan pada hotel di kota Surabaya dan Medan, karena variabel lokasi dan harga tidak muncul sebagai variabel yang signifikan berpengaruh pada penelitian ini.

\subsubsection{Tingkat Loyalitas Tamu Hotel}

Pada penelitian ini, loyalitas tamu hotel ditunjukkan dengan minat tamu hotel untuk menggunakan jasa CGHR di masa yang akan datang dan minat tamu hotel untuk merekomendasikan CGHR kepada kerabat.

Nilai rata-rata dari seluruh responden untuk kedua pernyataan tersebut adalah 2.849 dari skala 4 , dimana loyalitas tertinggi dinyatakan dengan nilai 4 . Hal ini menunjukkan bahwa tingkat loyalitas tamu hotel CGHR belum tinggi, karena masih dibawah 3.

Dengan peningkatan dan perbaikan variabel-variabel kepuasan yang berpengaruh pada loyalitas diharapkan loyalitas tamu hotel akan meningkat.

\subsubsection{Penggabungan Hasil Pengolahan Data}

Berdasarkan metode Regresi Berganda, metode IPA dan pengujian hipotesis rata-rata, dapat ditentukan prioritas perbaikan/pengembangan yang harus dilakukan oleh perusahaan, sebagai berikut: 
USULAN STRATEGI PENINGKATAN LOYALITAS PELANGGAN (Stephanus Y., dkk.)

Tabel 6. Penggabungan Hasil Pengolahan Data

\begin{tabular}{|c|c|c|c|c|c|c|}
\hline No & Variabel & $\begin{array}{l}\text { Hasil Regresi } \\
\text { Berganda }\end{array}$ & $\begin{array}{l}\text { Hasil Pengujian } \\
\text { Hipotesis }\end{array}$ & $\begin{array}{c}\text { Hasil } \\
\text { IPA }\end{array}$ & $\begin{array}{c}\text { Nilai Z Hitung } \\
\text { Pengujian } \\
\text { Hipotesis }\end{array}$ & $\begin{array}{c}\text { Prioritas } \\
\text { Perbaikan }\end{array}$ \\
\hline 1 & 30 & \multirow{4}{*}{ Pengaruh } & \multirow{4}{*}{ Tidak Puas } & 2 & -14.892 & 1 \\
\hline 2 & 13 & & & 1 & -1.737 & 2 \\
\hline 3 & 32 & & & \multirow{2}{*}{4} & -10.742 & 3 \\
\hline 4 & 26 & & & & -2 & 4 \\
\hline 5 & 25 & \multirow{32}{*}{ Tidak Pengaruh } & \multirow{20}{*}{ Tidak Puas } & \multirow{3}{*}{2} & -16.024 & 5 \\
\hline 6 & 33 & & & & -12.063 & 6 \\
\hline 7 & 7 & & & & -3.802 & 7 \\
\hline 8 & 4 & & & \multirow{5}{*}{1} & -11.212 & 8 \\
\hline 9 & 34 & & & & -7.771 & 9 \\
\hline 10 & 16 & & & & -7.268 & 10 \\
\hline 11 & 17 & & & & -6.845 & 11 \\
\hline 12 & 29 & & & & -6.718 & 12 \\
\hline 13 & 36 & & & \multirow{7}{*}{3} & -10.219 & 13 \\
\hline 14 & 31 & & & & -9.56 & 14 \\
\hline 15 & 9 & & & & -9.37 & 15 \\
\hline 16 & 1 & & & & -8.47 & 16 \\
\hline 17 & 12 & & & & -8.099 & 17 \\
\hline 18 & 15 & & & & -6.801 & 18 \\
\hline 19 & 11 & & & & -5.929 & 19 \\
\hline 20 & 27 & & & \multirow{5}{*}{4} & -4.505 & 20 \\
\hline 21 & 3 & & & & -4.33 & 21 \\
\hline 22 & 2 & & & & -3.217 & 22 \\
\hline 23 & 28 & & & & -2.694 & 23 \\
\hline 24 & 10 & & & & -2.391 & 24 \\
\hline 25 & 19 & & \multirow{12}{*}{ Puas } & 1 & -0.721 & 25 \\
\hline 26 & 5 & & & \multirow{11}{*}{4} & -1.432 & 26 \\
\hline 27 & 24 & & & & -0.44 & 27 \\
\hline 28 & 8 & & & & -0.381 & 28 \\
\hline 29 & 20 & & & & 0.449 & 29 \\
\hline 30 & 18 & & & & 0.506 & 30 \\
\hline 31 & 14 & & & & 0.724 & 31 \\
\hline 32 & 6 & & & & 0.824 & 32 \\
\hline 33 & 21 & & & & 2.03 & 33 \\
\hline 34 & 35 & & & & 2.07 & 34 \\
\hline 35 & 22 & & & & 2.081 & 35 \\
\hline 36 & 23 & & & & 2.144 & 36 \\
\hline
\end{tabular}


Prioritas utama diberikan pada variabel kepuasan yang secara statistik berpengaruh terhadap variabel loyalitas, yaitu prioritas perbaikan 1 hingga 4. Berikut adalah urutan prioritas perbaikan/peningkatan variabel yang harus dilakukan oleh CGHR.

Tabel 7. Prioritas Perbaikan/Peningkatan

\begin{tabular}{|c|c|c|c|}
\hline No & $\begin{array}{c}\text { No } \\
\text { Variabel }\end{array}$ & Variabel & Prioritas \\
\hline 1 & 30 & Frekuensi diberikannya diskon & 1 \\
\hline 2 & 13 & Variasi menu breakfast & 2 \\
\hline 3 & 32 & Kemudahan check in & 3 \\
\hline 4 & 26 & Kemampuan komunikasi satpam & 4 \\
\hline 5 & 25 & Kecepatan satpam dalam membantu memarkirkan kendaraan & 5 \\
\hline 6 & 33 & Kemudahan check out & 6 \\
\hline 7 & 7 & Kelengkapan fasilitas kamar mandi (handuk, sikat gigi dll) & 7 \\
\hline 8 & 4 & Pencahayaan kamar & 8 \\
\hline 9 & 34 & Kebersihan peralatan makan & 9 \\
\hline 10 & 16 & Kemudahan parkir & 10 \\
\hline 11 & 17 & Keamanan tempat parkir & 11 \\
\hline 12 & 29 & Kesesuaian tarif hotel dengan fasilitas yang diberikan & 12 \\
\hline 13 & 36 & Kenyamanan kursi di ruang tunggu (lobby) & 13 \\
\hline 14 & 31 & Kemenarikan promosi melalui instagram & 14 \\
\hline 15 & 9 & Kenyamanan tempat duduk di restaurant & 15 \\
\hline 16 & 1 & Kebersihan kamar & 16 \\
\hline 17 & 12 & Kelezatan rasa breakfast & 17 \\
\hline 18 & 15 & Kejelasan petunjuk jalan menuju hotel & 18 \\
\hline 19 & 11 & Kenyamanan suhu di restaurant & 19 \\
\hline 20 & 27 & Kesopanan satpam terhadap tamu & 20 \\
\hline 21 & 3 & Kesejukan kamar & 21 \\
\hline 22 & 2 & Variasi jenis kamar & 22 \\
\hline 23 & 28 & Kerapihan pakaian satpam & 23 \\
\hline 24 & 10 & Kenyamanan pencahayaan di restaurant & 24 \\
\hline 25 & 19 & Kecepatan receptionist dalam membantu tamu & 25 \\
\hline 26 & 5 & Aroma kamar & 26 \\
\hline 27 & 24 & Keramahan satpam & 27 \\
\hline 28 & 8 & Kelengkapan fasilitas kamar (tv, sandal, kulkas, dll) & 28 \\
\hline 29 & 20 & Ketepatan receptionist & 29 \\
\hline 30 & 18 & Keramahan receptionist & 30 \\
\hline 31 & 14 & Toleransi pihak hotel menentukan waktu check out & 31 \\
\hline 32 & 6 & Penataan kamar & 32 \\
\hline 33 & 21 & Kemampuan komunikasi receptionist & 33 \\
\hline 34 & 35 & Kebersihan ruang tunggu (lobby) & 34 \\
\hline 35 & 22 & Kesopanan receptionist terhadap tamu & 35 \\
\hline 36 & 23 & Kerapihan pakaian receptionist & 36 \\
\hline
\end{tabular}

Dengan perbaikan dan peningkatan yang dilakukan oleh CGHR, loyalitas tamu hotel diharapkan akan meningkat. 


\subsubsection{Pengolahan Profil Konsumen}

Tabel dibawah ini menunjukkan profil responden penelitian ini:

Tabel 8. Profil Konsumen

\begin{tabular}{|c|c|c|c|c|c|}
\hline Profil & Jumlah & $\%$ & Profil & Jumlah & $\%$ \\
\hline \multicolumn{3}{|l|}{ Usia } & \multicolumn{3}{|c|}{ Penghasilan per bulan } \\
\hline 17 tahun $<$ Usia $<24$ tahun & 6 & 5.66 & Penghasilan $<5$ juta & 24 & 22.64 \\
\hline 24 tahun $\leq$ Usia $<35$ tahun & 79 & 74.53 & 5 juta $\leq$ penghasilan $<10$ juta & 57 & 53.77 \\
\hline 35 tahun $\leq$ Usia $<45$ tahun & 17 & 16.04 & 10 juta $\leq$ penghasilan $<6$ juta & 16 & 15.09 \\
\hline 45 tahun $\leq$ Usia $<55$ tahun & 3 & 2.83 & Penghasilan $\geq 15$ juta & 9 & 8.49 \\
\hline$>55$ tahun & 1 & 0.94 & \multicolumn{3}{|c|}{ Perolehan informasi } \\
\hline \multicolumn{3}{|c|}{ Jenis Kelamin } & Keluarga & 8 & 7.55 \\
\hline Laki - laki & 90 & 84.91 & Internet & 83 & 78.30 \\
\hline Perempuan & 16 & 15.09 & Teman & 15 & 14.15 \\
\hline \multicolumn{3}{|c|}{ Pekerjaan } & \multicolumn{3}{|c|}{ Media sosial yang sering digunakan } \\
\hline Mahasiswa & 3 & 2.83 & Facebook & 76 & 42.70 \\
\hline Pegawai negeri & 2 & 1.89 & Instagram & 102 & 57.30 \\
\hline Karyawan Swasta & 38 & 35.85 & & & \\
\hline Wiraswasta & 57 & 53.77 & Cara Pembay & & \\
\hline Ibu rumah tangga & 6 & 5.66 & Debit & 60 & 37.97 \\
\hline \multicolumn{3}{|l|}{ Kota Asal } & Kartu Kredit & 88 & 55.70 \\
\hline Cimahi & 2 & 1.89 & Tunai & 9 & 8.49 \\
\hline Jakarta & 45 & 42.45 & Transfer & 1 & 0.63 \\
\hline Bandung & 33 & 31.13 & & & \\
\hline Cirebon & 2 & 1.89 & \multicolumn{3}{|c|}{ Bank yang digunakan } \\
\hline Surabaya & 1 & 0.94 & BCA & 80 & 57.55 \\
\hline Bogor & 2 & 1.89 & MANDIRI & 47 & 33.81 \\
\hline Manado & 1 & 0.94 & HSBC & 4 & 2.88 \\
\hline Depok & 1 & 0.94 & NIAGA & 4 & 2.88 \\
\hline Subang & 7 & 6.60 & $\mathrm{BNI}$ & 3 & 2.16 \\
\hline Bandar Lampung & 1 & 0.94 & BRI & 1 & 0.72 \\
\hline Tangerang & 11 & 10.38 & & & \\
\hline \multicolumn{3}{|c|}{ Promo yang disukai } & \multicolumn{3}{|c|}{ Proses pemesanan yang disukai } \\
\hline $\begin{array}{l}\text { Potongan harga untuk hari } \\
\text { kedua }\end{array}$ & 8 & 7.55 & Booking melalui website & 61 & 57.55 \\
\hline $\begin{array}{l}\text { Voucher untuk menginap } \\
\text { selanjutnya }\end{array}$ & 69 & 65.09 & Booking melalui telepon & 5 & 4.72 \\
\hline $\begin{array}{l}\text { Free coffee di coffee shop } \\
\text { Clove Garden }\end{array}$ & 16 & 15.09 & Datang langsung & 3 & 2.83 \\
\hline Potongan harga & 13 & 12.26 & Traveloka dan sejenisnya & 37 & 34.91 \\
\hline \multicolumn{3}{|c|}{$\begin{array}{c}\text { Tarif CGHR dibanding } \\
\text { hotel lain yang setara di Bandung }\end{array}$} & \multicolumn{3}{|c|}{$\begin{array}{l}\text { Pemandangan CGHR dibanding } \\
\text { hotel lain yang setara di Bandung }\end{array}$} \\
\hline Relatif lebih murah & 85 & 80.19 & Relatif lebih bagus & 1 & 0.94 \\
\hline Relatif sama & 17 & 16.04 & Relatif sama & 25 & 23.58 \\
\hline Relatif lebih mahal & 4 & 3.77 & Relatif lebih bagus & 80 & 75.47 \\
\hline
\end{tabular}

Tabel profil diatas digunakan untuk penetapan target pasar CGHR, sehingga CGHR dapat membuat positioning yang tepat dan selanjutnya menyusun strategi dan perbaikan yang tepat untuk meningkatkan loyalitas tamu hotel. 
Berdasarkan penelitian, disarankan CGHR untuk memilih target pasar usia 24 tahun $\leq$ usia $<35$ tahun, yang berasal dari Jakarta dan Bandung, dengan pekerjaan wiraswasta dan karyawan swasta dengan golongan ekonomi menengah, aktif menggunakan internet dan sering menggunakan instagram dan facebook, sering menggunakan kartu kredit dan debit untuk pembayaran yaitu bank BCA dan Mandiri, menyukai promo berupa voucher untuk menginap selanjutnya, dan menyukai proses pemesanan dengan booking melalui website resmi CGHR serta online booking lainnya.

Tabel diatas juga menunjukkan bahwa tamu hotel menilai tarif CGHR relatif lebih murah dibanding hotel lain yang setara di Bandung, selain itu pemandangan CGHR dinilai relatif lebih bagus dibandingkan hotel lain yang setara di Bandung,

Saat ini CGHR memiliki slogan " "Stop Paying More”. Berdasarkan hasil penelitian, diusulkan slogan baru yaitu "Comfort, Green Environment, Fast Service and Pay Less". Usulan slogan ini berdasarkan variabel yang secara signifikan berpengaruh terhadap loyalitas, variabel yang sangat dipentingkan oleh tamu hotel dan variabel yang sudah memuaskan tamu hotel, juga memperhatikan targeting di atas.

\section{Kesimpulan dan Saran}

(1) Berdasarkan metode IPA, prioritas perbaikan utama dilakukan pada variabel yang berada pada kuadran II (sejumlah 5 variabel), prioritas perbaikan selanjutnya adalah variabel pada kuadran III (sejumlah 7 variabel), kemudian perbaikan pada variabel bauran pemasaran di kuadran I (sejumlah 7 variabel) dan terakhir perbaikan dilakukan pada variabel bauran pemasaran di kuadran IV (sejumlah 17 variabel).

(2) Hasil pengujian hipotesis rata-rata menunjukkan bahwa dari 36 variabel bauran pemasaran, hanya 12 variabel yang telah memuaskan tamu hotel, dan variabel yang paling belum memuaskan tamu hotel adalah variabel 25 yaitu Kecepatan satpam dalam membantu memarkirkan kendaraan.

(3) Pengolahan Regresi Berganda dengan metode stepwise menghasilkan 4 variabel kepuasan yang secara signifikan berpengaruh terhadap loyalitas konsumen yaitu Kemampuan Komunikasi Satpam, Variasi Menu Breakfast, Kemudahan Check In, dan Frekuensi Diberikannya Diskon. Seluruh nilai koefisien regresi variabel kepuasan bernilai positif, artinya seluruh variabel kepuasan tersebut memiliki pengaruh positif pada loyalitas.

Nilai koefisien korelasi (R) positif yang kuat yaitu sebesar 0.846 , dan nilai koefisien determinasi $\left(\mathrm{R}^{2}\right)$ sebesar 0.716, artinya sebesar $71.6 \%$ dari loyalitas konsumen CGHR dapat dijelaskan oleh keempat variabel kepuasan, sedangkan sisanya sebesar $28.4 \%$ dijelaskan oleh variabel lain yang tidak diteliti dalam penelitian ini.

(4) Hasil pengolahan regresi berganda pada penelitian ini menyatakan bahwa loyalitas tamu hotel di CGHR dipengaruhi oleh variabel manusia, produk dan promosi. Hasil penelitian ini berbeda dengah kedua hasil penelitian mengenai hotel sebelumnya yang dilakukan pada hotel di kota Surabaya dan Medan, karena variabel lokasi dan harga tidak muncul sebagai variabel yang signifikan berpengaruh pada penelitian ini.

(5) Loyalitas tamu hotel ditunjukkan dengan minat tamu hotel untuk menggunakan jasa CGHR di masa yang akan datang dan minat tamu hotel untuk merekomendasikan CGHR kepada kerabat. Nilai rata-rata untuk kedua pernyataan tersebut adalah 2.849 dari skala 4, artinya tingkat loyalitas tamu hotel CGHR belum tinggi, karena masih dibawah 3 .

(6) Target pasar yang diusulkan adalah usia 24 tahun $\leq$ usia $<35$ tahun, yang berasal dari Jakarta dan Bandung, dengan pekerjaan wiraswasta dan karyawan swasta dengan golongan ekonomi menengah, aktif menggunakan internet dan sering menggunakan instagram dan facebook, sering menggunakan kartu kredit dan debit untuk pembayaran yaitu bank BCA dan Mandiri, 
menyukai promo berupa voucher untuk menginap selanjutnya, dan menyukai proses pemesanan dengan booking melalui website resmi CGHR serta online booking lainnya.

Berdasarkan hasil penelitian diusulkan slogan baru yaitu "Comfort, Green Environment, Fast Service and Pay Less".

(7) Untuk meningkatkan loyalitas tamu hotel, CGHR disarankan untuk melakukan perbaikan/peningkatan sesuai prioritas perbaikan yang dibuat sebelumnya. Berikut adalah prioritas perbaikan utama, yaitu:

Prioritas 1: Frekuensi diberikannya diskon (Var 30)

Prioritas 2: Variasi menu breakfast (Var 13).

Prioritas 3: Kemudahan check in (Var 32),

Prioritas 4: Kemampuan komunikasi satpam (Var 26)

(8) Usulan utama bagi CGHR:

- Memberikan kupon diskon untuk menginap berikutnya, karena berdasarkan kuesioner konsumen senang dengan diskon untuk menginap berikutnya (65.09\%). Sebaiknya kupon langsung diberikan saat check out, sehingga tamu hotel yakin akan keabsahan kupon diskon tersebut. Diskon sebaiknya diberikan saat low season.

- Kekurangan pada variabel Variasi menu breakfast ternyata sudah disadari oleh pihak CGHR. Disarankan penyediaan berbagai juice untuk breakfast, juga berbagai makanan khas Bandung secara bergantian dan terjadwal.

- Kelambatan proses check out berimbas pada keterlambatan tamu baru yang akan check in. Karena itu, disarankan pihak hotel memperketat peraturan waktu check out sehingga tidak merugikan tamu yang akan check in. Umumnya aturan terkait check out adalah denda jika terlambat atau tamu hotel diwajibkan untuk menyewa kamar kembali secara penuh atau setengah hari. Selain itu, pihak CGHR juga harus mengontrak pegawai paruh waktu pada saat peak season.

- Berdasarkan observasi, satpam CGHR tampaknya merasa kurang percaya diri jika harus berkomunikasi dengan tamu hotel. Disarankan adanya pelatihan komunikasi sederhana dan training untuk peningkatan kepercayaan diri karyawan hotel, terutama satpam. Satpam juga dapat dilibatkan dalam briefing-briefing agar memahami kegiatan-kegiatan yang akan dilakukan CGHR.

\section{Daftar Pustaka}

Ghozali, Imam (2006), Aplikasi Analisis Multivariate dengan Program SPSS, Cetakan keempat, Badan Penerbit Universitas Diponegoro, Semarang.

Hair, Anderson, Tatham \& Black (2010), Multivariate Data Analysis, $7^{\text {th }}$ edition, Prentice-Hall International, Inc., USA

Kotler (2004), Manajemen Pemasaran, jilid 1, Edisi Revisi, PT Prenhallindo, Jakarta.

Lind, Marchal, Wathen (2012), Statistical Techniques in Business and Economics, $15^{\text {th }}$ edition, McGraw Hill, Irwin

Margono (2003), Metodologi Penelitian Pendidikan, PT. Rineka Cipta, Jakarta

Stellamaris, Sutanto (2019), Analisis Pengaruh Kesesuaian Harga, Efektivitas Promosi Dan Kualitas Pelayanan Terhadap Loyalitas Pelanggan Zest Hotel Jemursari Surabaya, Jurnal AGORA Vol. 7, No. 1

Sugiyono (2004), Statistika Untuk Penelitian, CV. Alfabeta, Bandung

Sugiyono (2011), Metode Penelitian Administrasi, cetakan kesembilan, CV.Alfabeta, Bandung 
JOURNAL OF INTEGRATED SYSTEM VOL 2. NO. 2, DESEMBER 2019: 208-225

Supranto, J. (2001), Pengukuran Tingkat Kepuasan Pelanggan untuk Menaikkan Pangsa Pasar, PT Rineka Cipta, Jakarta

Timm, Paul R. (2001), Seven Power Strategies for Building Customer Loyalty, New York: American Management Association.

Winata, E. (2017), Pengaruh Bauran Pemasaran Jasa Terhadap Loyalitas Konsumen Pada Grand Serela Hotel \& Convention Medan, Jurnal Mutiara Manajemen, Vol. 2 No. 1, pp.104-117

Yulianti, Stevan (2018), Usulan Strategi Bauran Pemasaran untuk Meningkatkan Frekwensi Kedatangan Konsumen ke RM. Swieke Ibu Kristina, Karawang Barat, Journal of Integrated System Vol. 1 No. 1, pp. 20-33 